\title{
Chronic breathlessness: symptom or syndrome?
}

\author{
Peter M.A. Calverley \\ Affiliation: School of Ageing and Chronic Disease, University Hospital Aintree, Liverpool, UK. \\ Correspondence: Peter M.A. Calverley, Clinical Science Centre, University Hospital Aintree, Liverpool, UK. \\ E-mail: pmacalaliverpool.ac.uk
}

@ERSpublications

Chronic breathlessness needs more attention than it presently receives http://ow.ly/d3oN30aCImf

Cite this article as: Calverley PMA. Chronic breathlessness: symptom or syndrome? Eur Respir J 2017; 49: 1700366 [https://doi.org/10.1183/13993003.00366-2017].

\begin{abstract}
Maybe it's my age. As a young doctor I was keen to understand the mechanisms of disease in the hope that I could repair what had gone wrong. But now I spend more time in reflection on what illness means to the patient and how it affects their lives. There is nothing new in this process, which was beautifully documented in the book A Fortunate Man by the late John Berger about the life and work of John Sassall, a doctor in a rural area of the UK [1]. For most of my career, breathlessness has been the commonest symptom reported by my patients. Despite its ubiquity, we still struggle to understand the mechanisms that underlie this sensation and the way in which it is perceived by our patients. From the doctor's and carer's perspective, breathlessness is, all too often, an invisible symptom [2] but one that can dominate the patient's life either as a source of immediate distress or as a threat that limits their ability to engage with others and retain their independence.
\end{abstract}

We have moved on from the time when the great Julius Comroe suggested that a respiratory physiologist offering a unitary explanation for breathlessness, "should arouse the same suspicions as a tattooed archbishop offering a free ticket to heaven" [3]. Advances in neuroimaging have identified areas within the cortico-limbic system that are consistently associated with breathlessness in health and disease [4]. Debate continues about differences in the qualitative character of the sensation of breathlessness patients experience, with sufferers from a range of diseases reporting similar clusters of symptom descriptors, which differ from the way healthy people describe more physiological breathlessness [5]. The intensity of breathlessness in health and respiratory disease is related to neural respiratory drive, which can be measured with some precision using new multi-polar oesophageal electrodes [6]. How this signal is related to afferent feedback through a variety of mechanisms is still unclear. There is increasing evidence to support the concept of a central role for the motor contribution in the cerebral cortex in driving the perception of breathlessness [7]. Breathlessness undoubtedly serves as a physiological warning of potentially catastrophic system failure, as seen from the way it parallels the onset of respiratory muscle fatigue in experimental studies [8]. Recent work has shown that the multidimensional nature of this symptom can be captured and for the first time quantified, an advance that will help our future understanding substantially [9-11].

Like pain, breathlessness provokes changes in behaviour that lessen the burden on the cardiorespiratory system. This has clear evolutionary advantages and we should not be surprised that we tamper with this process at our peril. In disease states, the best way to relieve breathlessness is to treat the underlying condition effectively, something that is not always possible. Managing the symptom of breathlessness in isolation, a very effective approach with pain control, has proven to be difficult. Opioids are effective in

Received: Feb 212017 | Accepted after revision: March 282017

Conflict of interest: None declared.

Copyright CERS 2017 
reducing breathlessness but at the cost of promoting ventilatory depression and of producing a range of unwelcome side-effects [12]. Unsurprisingly, their use is largely limited to end-of-life care when the need for symptom control is paramount. For many patients, living with chronic breathlessness means adapting their lives to the limits it imposes on their daily activity, something that can be present at early stages in some chronic respiratory diseases [13].

In this issue of the European Respiratory Journal, a perspective article by JoHnson et al. [14] calls on us to change our approach to patients with chronic breathlessness. They report in detail the results of a Delphi consultation process conducted to identify whether experts in a range of relevant disciplines felt that there was a need to identify a chronic breathlessness syndrome and if so, how it should be defined. The process involved the input of only 13 people but all had a particular interest and expertise in this area so their views carry some weight. Unsurprisingly, most considered that the term chronic breathlessness syndrome was the best one to use to describe patients with persisting breathlessness that impacted adversely on their lives and was present despite optimal evidence-based treatment. By analogy with other syndromic diagnostic groups like chronic pain and the obstructive sleep apnoea syndrome, they felt that there were considerable advantages to identifying patients in this way.

Inevitably in this field there will be arguments about what exactly is meant by this new terminology. For some, the term chronic may be a problem as it seems to exclude consideration of patients who remain breathless despite optimal support in acute settings like mechanical ventilation [15]. JoHNSON et al. [14] considered the term persistent breathlessness but opted by a majority vote for chronic breathlessness syndrome. Pesonally, I am not entirely convinced by the arguments that these patients comprise a discrete syndrome. I can see the advantages of identifying a series of clinical features that "run together", the literal meaning of the word syndrome. This was the approach we took when we defined the obstructive sleep apnoea syndrome (OSAS) (later adding hypopneas as well). At that stage, we were still trying to understand how the pathophysiology of this recently described condition related to its clinical features and risk factors. This work has been largely completed and as a result, relatively few people now speak of OSAS rather than OSA. The recent history of the asthma-COPD overlap syndrome suggests that a term that appeared to meet a clinical need is not necessarily one that identifies consistent groups of patients or adds more than a clearer description of the most likely primary condition could, a point acknowledged by the authors who coined the term originally [16]. It never helps if discussion about the meaning of the label becomes more important than the needs of the patients it is intended to help.

However, there is much less to contest in the authors' other conclusions. Promoting an interest in and recognition of the problems of patients with chronic breathlessness can only be a good thing. As a tool for advocacy and an aid to the quantification of the social and economic impact of breathlessness, the term has much to recommend it. There is an urgent need to understand more about the mechanisms of breathlessness and how we can safely reduce the impact of this symptom on patients' lives. Use of the term chronic breathlessness syndrome could be an aid to doing this, provided those who research this topic are explicit about describing the characteristics and intensity of the breathlessness in their patients in a standardised fashion. Mechanistic studies that use modern technologies to explain why and in what settings chronic breathlessness develops are long overdue. Finally, the development of effective services to optimise care, especially non-pharmacological approaches to breathlessness management, is likely to be very helpful and some evidence to support this idea is now being reported [17].

JoHnson et al. [14] have done our community a service by highlighting the plight of the large number of patients who remain symptomatic despite our best efforts. Rightly they want to move the idea of palliating symptoms beyond the field of end-of-life care. Whether these patients should be classified as having a specific syndrome is still open to debate which can be taken forward through the correspondence column of this journal not to mention the associated electronic media now available. Nonetheless, there can be no doubt that patients who report being chronically breathless deserve better care and more attention than is currently the case.

\section{References}

Berger J, Mohr J. A Fortunate Man. London, The Penguin Press, 1967.

2 Gysels M, Higginson IJ. Access to services for patients with chronic obstructive pulmonary disease: the invisibility of breathlessness. J Pain Symptom Manage 2008; 36: 451-460.

3 Comroe JJ. Some theories on the mechanism of dyspnea. In: Howell J, Campbell E, eds. Breathlessness. Oxford, Blackwell Scientific, 1966; pp. 1-7.

4 Jack S, Kemp GJ, Bimson WE, et al. Patterns of brain activity in response to respiratory stimulation in patients with idiopathic hyperventilation (IHV). Adv Exp Med Biol 2010; 669: 341-345.

5 Smith J, Albert P, Bertella E, et al. Qualitative aspects of breathlessness in health and disease. Thorax 2009; 64: 713-718.

6 Jolley CJ, Luo YM, Steier J, et al. Neural respiratory drive in healthy subjects and in COPD. Eur Respir J 2009; 33: 289-297. 
7 Georges M, Moraviec E, Raux M, et al. Cortical drive to breathe in amyotrophic lateral sclerosis: a dyspnoea-worsening defence? Eur Respir J 2016; 47: 1818-1828.

8 Clague JE, Carter J, Pearson MG, et al. Effect of sustained inspiratory loading on respiratory sensation and $\mathrm{CO}_{2}$ responsiveness in normal humans. Clin Sci (Lond) 1996; 91: 513-518.

9 Morélot-Panzini C, Gilet H, Aguilaniu B, et al. Real-life assessment of the multidimensional nature of dyspnoea in COPD outpatients. Eur Respir J 2016; 47: 1668-1679.

10 Banzett RB, O’Donnell CR, Guilfoyle TE, et al. Multidimensional Dyspnea Profile: an instrument for clinical and laboratory research. Eur Respir J 2015; 45: 1681-1691.

11 Williams MT, John D, Frith P. Comparison of the Dyspnoea-12 and Multidimensional Dyspnoea Profile in people with COPD. Eur Respir J 2017; 49: 1600773.

12 Parshall MB, Schwartzstein RM, Adams L, et al. An official American Thoracic Society statement: update on the mechanisms, assessment, and management of dyspnea. Am J Respir Crit Care Med 2012; 185: 435-452.

13 Watz H, Waschki B, Meyer T, et al. Physical activity in patients with COPD. Eur Respir J 2009; 33: 262-272.

14 Johnson MJ, Yorke J, Hansen-Flaschen J, et al. Towards an expert consensus to delinieate a clinical syndrome of chronic breathlessness. Eur Respir J 2017; 49: 1602277.

15 Schmidt M, Demoule A, Polito A, et al. Dyspnea in mechanically ventilated critically ill patients. Crit Care Med 2011; 39: 2059-2065.

16 Gibson PG, McDonald VM. Asthma-COPD overlap 2015: now we are six. Thorax 2015; 70: 683-691.

17 Higginson IJ, Bausewein C, Reilly CC, et al. An integrated palliative and respiratory care service for patients with advanced disease and refractory breathlessness: a randomised controlled trial. Lancet Respir Med 2014; 2: 979-987. 